\title{
Quality social work placements for Māori social work students
}

\author{
Hannah Mooney, (Ngāti Raukawa ki te tonga, Te Āti Awa, Ngā Rauru, Te Āti Haunui a Pāpārangi), \\ Michael Dale and Kathryn Hay \\ Massey University, Aotearoa New Zealand
}

\begin{abstract}
INTRODUCTION: Māori perspectives should be genuinely represented and integrated into social work education to ensure Māori and non-Māori social work students alike are prepared for working effectively in Aotearoa New Zealand. In field education, Māori students may have particular needs and expectations that should be considered by academic staff and placement host organisations. Consequently, the placement experience for Māori students should reflect these needs and expectations.
\end{abstract}

METHOD: As part of a wider research project which aimed to advance the quality of social work placements for Māori and Pasifika students, a hui was undertaken with a roopu (Māori branch) of the Aotearoa New Zealand Association of Social Work (ANZASW) in late 2014. This article focuses on their views of what constitutes a quality placement for Māori social work students. The project explored two key areas: what does a quality placement look like for Māori social work students and what can tertiary institutions do to better support Māori students to have a quality placement?

FINDINGS AND CONCLUSIONS: Participants emphasised the usefulness of placement preparedness, clear expectations and open communication prior to, and during, placement. The placement should also be culturally safe and adequately challenge the student. Tertiary providers should support the student's placement by being in regular face-to-face contact; preparing the student for the placement environment; supporting external cultural supervision; and by critically reviewing their curriculum.

KEYWORDS: Māori; Indigenous; social work; field education; quality placements; students

AOTEAROA NEW ZEALAND SOCIAL WORK 32(3), 54-67.

CORRESPONDENCE TO: Hannah Mooney

H.A.Mooney@massey.ac.nz
A social work placement is an essential part of social work education. It is the place where theory and practice connect, and the social work student has the opportunity to consider the realities of the workplace. In Aotearoa New Zealand, the Social Workers Registration Board (SWRB) stipulates that students studying for social work qualifications at degree level are required to undertake a minimum of 120 days of field education during the final two years of their programme (SWRB, 2019). Social work students must have at least two placements in two differently structured settings and fields of practice and students are required to have weekly supervision with a registered social worker (SWRB, 2019).

A unique feature of the Aotearoa New Zealand social work profession is a commitment to Te Tiriti o Waitangi-a bicultural partnership that should 
underpin education, policy, and practice. It is essential that Māori are supported to become social workers so that there is a strong Māori social service workforce implementing Māori practice approaches. This is particularly important when Māori are overrepresented as users of social services and contend with institutional racism. Māori perspectives also need to be represented and integrated into social work education in order to ensure all students are prepared for working effectively in Aotearoa New Zealand. In field education, Māori students may have particular needs that should be considered by academic staff and the placement host organisations. Consequently, the placement experience for Māori students should take these needs and expectations into account.

As part of a wider research project which aimed to advance the quality of social work placements for Māori and Pasifika students, a hui was undertaken with a roopu (Māori branch) of the Aotearoa New Zealand Association of Social Work (ANZASW) in late 2014. This article focuses on their views of what constitutes a quality placement for Māori social work students. In the next section, consideration is given to salient aspects of the field education context, with a particular focus on the experience of indigenous students. The methods used in the study are then noted, before the findings from the hui are presented. In the final section, the findings are discussed and implications regarding field education placements for Māori social work students are identified, along with recommendations for practice.

\section{The context of field education placements}

This section draws upon both international and Aotearoa New Zealand sources to consider: the importance of placements within social work programmes; field education for indigenous students; and factors that contribute to a quality placement.

\section{The importance of placements}

The centrality of field education placements to student learning is well documented; however, there are concerns that it is under-resourced (Douglas, 2011; Hay, 2018; Maidment, 2000). In Aotearoa New Zealand, social work receives 35\% less funding per student from the Tertiary Education Commission than other areas that require work-integrated learning, such as education and health sciences (Tertiary Education Commission, 2020). Implications for field education are significant as placement host organisations receive no financial compensation to support placement students, adding to the difficulty in gaining placements, especially when the sector is under-resourced. In particular, the SWRB requirement that students receive weekly individual supervision with a registered social worker can present a challenge for agencies. The current practice environment in Aotearoa New Zealand is that there is increased competition for field education placements due to competition amongst education providers and limited placement availability in some locations (Hay, 2018).

In Aotearoa New Zealand, the programme recognition standards set by the SWRB contain specific requirements. Students completing a social work qualification must be able to demonstrate the achievement of core competencies at the completion of the qualification (SWRB, 2019). The field education placement is where students typically demonstrate these competencies, and Standard 1 requires that competence to practise social work with Māori is achieved (SWRB, 2019).

\section{Field education for Indigenous students}

Social work education internationally is dominated by western frameworks; however, Māori have a particular worldview that needs to be respected and nurtured in social work practice and education. In a placement context, 
professional enculturation can occur where Indigenous students are likely to engage with non-Indigenous frameworks (Cleak \& Wilson, 2018; Zuchowski, Savage, Miles, \& Gair, 2013). If Māori practice approaches and tikanga are not entrenched in a placement organisation, Māori students may find it especially challenging to observe, experience and critique their culturally appropriate models and concepts. Drawing on the work of Eketone and Walker (2016) who discuss the nature of Kaupapa Māori theory, decolonisation and its alignment with anti-oppressive critical approaches, current pedagogy can be challenged so that the validity of Māori knowledge becomes integrated, accepted and inherent in the curriculum and practice of field education.

Hollis-English's (2015) research into Māori social work approaches noted that Māori draw on Mātauranga Māori in their practice. "They come from a particular worldview that is influenced by one's experiences of being connected to a whānau, hapū and iwi, being indigenous in Aotearoa New Zealand and having embedded in one's ancestry, specific values and traditions belonging to that culture" (p. 6). She reinforced that this is best practice with whānau Māori accessing services. A key implication identified by HollisEnglish is the need for tertiary providers and social service organisations to support Māori social workers (and students) to utilise their own approaches. This raises a question as to what approaches might be best practice for Māori students in social work field education and how the tertiary provider can best support this. In Aotearoa New Zealand there are two kaupapa Māori social work programmes, and $17 \%$ of placements in 2019 were in Iwi or Māori organisations (SWRB, 2019). It is not, however currently known how many of the tertiary providers place their students in kaupapa Māori placements and whether any specific teaching and support is given to these students, either before or during their placements.
In Australia, Gair, Miles, Savage, and Zuchowski (2015) explored the placement experience for Aboriginal and Torres Strait Islander students. They found that many of the students experienced both subtle and overt racism while on placement, parallel to their daily lived experiences. Participants noted that they found other Indigenous students and workers helped them to cope with these issues while on placement. They recommended that students be supported by a cultural mentor (with or without social work qualifications) and suggested that further preparation for placement be undertaken, as one participant stated, "Take them out, introduction to the workplace ... their policy and stuff, how they can be supported ... how they work culturally in that organisation" (Gair et al., 2015 , p. 44). An additional recommendation was that field educators be screened for cultural suitability. Non-Indigenous field educators are not always able to provide safe placements, therefore more Indigenous field educators supporting Indigenous placement students are required and the student's lived experience needs to be given more credibility. The authors recommended several strategies to support Indigenous students including placement preparation by the agency staff; cultural support and mentors for the students; increasing Aboriginal and Torres Strait Islander academic staff; and anti-racism strategies in the universities and placement organisations.

In Canada, a collaborative study comparing the experience of Aboriginal and non-Aboriginal students on field placement in Aboriginal agencies was conducted (Clark et al., 2010). It found that decolonising field education programmes and teaching students about the historical and current implications of colonisation should be emphasised. The participants highlighted the importance of having cultural practices available and included in their education, such as through spirituality and ceremony, inclusion of elders, and responsiveness to, and understanding of, grief and loss practices. 
Other areas noted were the importance of a relational, supportive approach, antioppressive placement experiences and the use of student wellness plans and self-care in placements. The research concluded that "cultural safety and intersectionality provide frameworks for transforming field education" (Clark et al., 2010, p. 22). The importance of developing an indigenous intersectionality framework for social work field education was also highlighted by Clark and colleagues (2012). This framework would incorporate complex and intersecting structural factors impacting on Indigenous social work students. They recommended an ongoing evaluation process that involves Indigenous students having input into the tertiary institutional processes including placement and having language framed around Indigenous rights, not Indigenous needs.

Social work is a value-laden profession and Māori social workers (and students) are consistently faced with cultural tensions in their practice (Watson, 2019). Watson's research focused on social workers having to manage tension within their own whānau when they access services, where Māori experiences of these tensions are often more pronounced given the intersecting dimensions of the personal, professional and cultural. There are difficulties when Māori social workers are walking in and navigating the two worlds of Te Ao Pākehā and Te Ao Māori (Watson, 2019). It is likely that Māori social work students also face these tensions, especially when they are placed in mainstream organisations. Forms of discrimination may also be apparent to students during placement. For instance, minority students in Gladstein and Mailicks' (1986) research mentioned that, during placement, they were only assigned clients from the same ethnic group. The organisations justified this as wanting to use students' cultural insight and/ or language skills but did not necessarily consider the learning needs of the student. These researchers also recommended the use of cultural role models and the development of specific, culturally sensitive support programmes to meet the students' unique needs.

In combination, these research examples signal the need for a closer examination of current practice by both tertiary providers and placement host organisations so that Māori students can have suitable and successful placements.

\section{Factors that contribute to a quality placement}

Education providers should increase their support to students during placement because a quality placement is seen to produce "better qualified social work practitioners" (Flanagan \& Wilson, 2018, p. 576). Several quality frameworks for field education have been developed, although none of these is specific to Indigenous students (Bogo, 2010; Hay, 2019). Bogo (2010) recommended four foundational principles: 1) that it takes place within an available and supportive relationship; 2) learners benefit from a balance between structure and autonomy in practice and learning; 3) learners need to develop reflective and conceptual capacities; and 4) observation, reflective discussion, and a provision of constructive feedback facilitates mastery of skills (Bogo, 2010, p. 105). In the Aotearoa New Zealand context, Hay (2019) identified quality components as including: 1) a student learning focus; 2) the student is wanted; 3) the student is suitable and ready; and 4) there is good stakeholder engagement.

Maidment (2000), also speaking from the Aotearoa New Zealand context, highlighted possible cultural bias in social work education. In her research, Māori student participants noted that they were not prepared for placement in a way that suited their learning styles and assessment methods were less effective for their learning. Māori participants considered orientation to field and agency and one-to-one supervision as very important to their learning. Maidment 
(2000), however, proposed that the integration of Indigenous frameworks in social work education were in a formative stage at that time.

An Australian study by Gair and Baglow (2018) noted that poverty and psychological distress was increasingly common among university students. They found that this was exacerbated for social work students who experienced increased financial stress and mental health vulnerabilities when undertaking compulsory placements. Placement requirements created additional pressure as students tried to balance paid work, placement and family. They noted that there was also less time available for self-care and reflection (Gair \& Baglow, 2018). Study awards, such as the now defunct non-government organisation (NGO) study awards in Aotearoa

New Zealand, reportedly assisted with these personal pressures, so that students were able to focus on their placement rather than financial difficulties (Yeung, Mooney, \& English, 2016). Māori were significant recipients of these awards (over $40 \%$ ) which were highly successful in assisting with qualification completion. Many Māori social workers were able to continue to contribute to their Iwi organisations and communities while they completed their studies as both the student and organisation were supported in these awards (Yeung, Mooney, English, \& O’Donoghue, 2019).

Indigenous students in British Columbia were found to be more vulnerable to stress and ill health in government placements (Aro, 2004). Therefore, particular care needs to be taken to ensure that Indigenous students are placed with supervisors who are sensitive to their needs. Indigenous students employ a number of strategies to rebalance their holistic health-good attention to self-care, engaging in cultural practices and development of support networks are themes that emerged as strategies for coping with the stress of the practicum. Further, improved preparedness prior to placement may help to alleviate increased anxiety in students undertaking placement (Kanno \& Koeske, 2010).

While preparedness may help, the quality of the supervisory relationship also has a significant impact on student satisfaction with a placement. Supervision is a crucial element of a student placement. In Aotearoa New Zealand, the SWRB (2019) requires that students receive one hour of supervision each week during placement. This must be provided by a registered social worker from within the placement agency, or externally.

Māori social work researchers have emphasised the importance of the tertiary institution satisfactorily preparing and resourcing students and field educators / supervisors. For example, Moorhouse (2014) found that students lacked an understanding of the purpose and nature of supervision and therefore did not understand what constituted an acceptable standard. She identified the need for students to be adequately prepared for supervision. Field educators should also understand the core components of supervision. In addition, cultural and Kaupapa Māori supervision should be considered and resourced in the same way as other forms of supervision (Moorhouse, 2014). Lipsham's (2016) research yielded similar results, including that students were not sufficiently prepared for placement supervision in the classroom prior to placement and needed increased opportunities for bicultural supervision.

A number of areas have been identified as influencing whether a placement is of quality, and while there are pre-existing frameworks to reference, none is specific to Indigenous students. The importance of placement preparedness is important for all students. However, Māori students have different placement needs and these should be carefully considered by tertiary staff. Supervision is a key component that should be resourced adequately to provide specific cultural support, particularly for Māori. 


\section{Method}

As mentioned, this article focuses on the findings from one component of a broader research project. The aims of this project were to:

a) Advance current knowledge on what constitutes quality social work placements for Māori and Pasifika students;

b) Enhance current teaching practice and institutional support of Māori and Pasifika students enrolled in placement papers;

c) Improve current institutional practices in respect of organising, monitoring and evaluating placements for Māori and Pasifika students.

The overall objective was to improve the practices of the Massey University Social Work Field Education programme, and better support Māori and Pasifika students prior to, and during, their placements. The intention was to add value to their placement experiences, assist with the retention of these cohorts of students and strengthen relationships with placement host organisations that may be supporting future Māori and Pasifika students.

This project utilised a qualitative methodology and explored the subjective views of Māori social work students (retrospectively) regarding what might constitute a quality placement. It was reviewed and approved by the Massey University Human Ethics Committee. A Māori-centred approach (Cunningham, 2000) was applied and the research was undertaken by a Māori researcher with attention to appropriate Māori processes and ethics. Māori-centred research can be applied when Māori are significant participants and senior members of a research team, a Māori analysis is utilised and Māori knowledge is produced (Cunningham, 2000).
Permission was sought and granted by the executive members of an ANZASW roopu (branch) to complete a hui following one of the bi-monthly roopu hui with roopu members opting out if they wished. The roopu members were invited to participate as they were Māori social workers who had experienced social work placements during their social work training. A hui is similar to that of a focus group; however, the language of hui is more culturally appropriate and means "gathering, meeting, assembly, seminar, conference" (Māori Dictionary, 2019). The researcher was a member of the roopu, so care was taken to highlight that the research role was separate from the usual participation in roopu activities. Participants were provided with an information sheet (outlining key information about the research including rights of the participants) and the interview questions via email and this was distributed by the roopu chair to roopu members prior to the roopu hui. Openended questions encouraged kōrero from participants regarding their views on quality placements for Māori social work students. Roopu members who were keen to participate signed a consent form prior to the hui.

Six members chose to participate, and they reflected on their experiences as students and as members of an agency supporting Māori students. Additionally, two of the participants reflected on their experience as field educators and supervisors of Māori placement students. Demographic data relating to the years of social work experience of the participants was not gathered. The tertiary providers they refer to are not named in this article, but it is important to note that the experiences were not all related to one tertiary provider. The hui was opened and closed with karakia and the researcher provided kai to indicate the process was complete and to thank the roopu for their time and contribution. The hui was audiotaped and transcribed by a Māori staff administrator from Massey University; individual participants were not identified in the transcript. The transcript was then analysed thematically and the results are 
presented below under two main headings: What does a quality placement look like for Māori social work students? and What can tertiary institutions do to better support Māori students to have a quality placement?

\section{Findings}

The following findings offer insight into Māori social workers' views on social work placements for Māori students. This section is structured into the two key themes above phrased as questions, with subthemes. The first theme asked about what a quality placement looks like for Māori social work students; while the focus of the second theme was what could tertiary institutions do to better support Māori students to have a quality placement.

\section{What does a quality placement look like for Māori social work students?}

For many of the participants, a quality placement included having clear expectations and open communication, a culturally safe environment, and an expectation that the student is open to being challenged.

\section{Clear expectations and open communication}

Preparation for placement was identified as critical. Māori social work students' need to understand the context of the placement agency (including location and history), placement expectations, and how their tertiary institution will support them. The Kaupapa (purpose) should be clear for all involved. One participant explained they complete interviews with students prior to placement to "...make sure that they fit and understand exactly what we' re looking for and expecting and vice versa." Both the student and the placement organisation have important roles setting up a quality placement:

We make sure we determine and define what it is, quality, from a student's point of view and from our point of view.
I think, you know, communication is essential. Good communication from the manager, supervisor and the staff ... Take responsibility for the student.

This practice was in response to observing other professional programmes in their organisation of placement (for example, nursing) and from experiences of placements that did not go well because misunderstandings had occurred. Defining expectations provided a chance to explore the student's level of learning and engagement. One participant preferred finalyear placements so that they could treat the student more like a colleague:

In order for them to get a quality placement they have to come with the mindset that they are a beginner practitioner and be ready ... They get supported but they actually are expected to behave professionally and ... plan their calendars and fulfil their obligations like they are actually working, and if they do that they tend to get a much better experience; they get treated like a staff member as opposed to, "You're just a student."

This organisation had considerable expectations of the student's initiative:

We make it a student responsibility. I as your field work educator or supervisor am not going to facilitate that for you. You're a social worker. Go and network, go and meet them, do it.

One participant mentioned that the placement should be at least 12 weeks in order for the students to fully integrate and develop relationships within the organisation. This was based on their experience of an eight-week placement when they were a student:

You have the whanaungatanga or getting to know the organisation that you're with, then you're getting to know the work, and you're going out with other 
workers, and then, you know, the ideal is that you have your own caseload; whereas I went in eight weeks... I didn't get the experience of "flying solo", if you like. So it's really important.

\section{A culturally safe environment}

The student feeling "culturally safe" was highlighted as an important factor for a quality placement. Participants agreed that the Māori social work student should be welcomed appropriately to the organisation through pōwhiri or mihi whakatau (formal cultural welcome processes). They should feel invited and wanted and have a solid orientation to the service "not just dumped in, 'this is where you're going to be working'." This welcome would include sharing kai (food and refreshments) together. This aligns with traditional Māori processes of formally entering situations and places.

All participants agreed that Māori students should be supported and allowed to be themselves, to "be Māori" in their social work placement. This was regardless of their level of knowledge of tikanga Māori and Te Reo Māori:

I think that for Māori students; being allowed to be Māori ...

...they will have that tikanga Māori ingrained, they may also have te reo ingrained, but there are others that may not, but they still acknowledge themselves as being Māori. So, you know, just being allowed to be who they are as Māori.

This highlighted the unique nature of placements for Māori students, that their cultural identity should be recognised and integrated into the placement setting. One way to support Māori students who are not in a Māori organisation could be through supervision:

...maybe hook them up with peer supervision or have external supervision, Māori with a cultural component ...
There was recognition that supervision should be formal and regular (occurring at a set time with an agenda) but also flexible to fit with the nature of the agency and work involved. An example of flexibility could be the supervision venue, for example, in the car or while sharing kai.

Supervision was viewed as essential for student learning and directly linked to the quality of placement. The supervisor should be organised, have a weekly plan, but also be adaptable:

... but I think in order to get a student through with quality they need to be, the person they're allocated to as a supervisor, needs to follow through and make sure that everything is done properly.

There was a suggestion that the field educator role and the supervision role be separated. This would mean the student was supported by two people in the organisation:

So any student coming into us now will get a field work educator and their supervisor internally is going to be a different person, and that's in recognising that if for whatever reason the student has a problem with their field work educator and that person is usually their supervisor as well they may not feel very comfortable talking about that so we have decided to split the role to help them get a better quality...

This separation was also considered beneficial when there were other experienced social workers available in the organisation to provide input and it lessened the field educator's workload.

The participants viewed external supervision as valuable. One suggestion was that this could be offered by the tertiary provider to retain the direct connection between all the parties involved in the placement:

We provide internal supervision, which is ideally weekly, I do think that for some 
students, not all, they would greatly benefit from external supervision from their institution as well.

Well we're providing like clinical supervision if you like around the actual work and what they are doing but that's very defined and for them to then be able to go and kōrero to a supervisor from school in their setting that helps them align what the school's expectation around their mahi and their assignments with what they're facing in reality. I think that would be useful ... They also need to sound off as well.

\section{Challenging the student}

Experiencing challenges increases the likelihood of students having a quality placement:

...well I myself, have to pull them out of that comfort zone and quite often it's like pulling teeth with some of them...

There was an expectation that students demonstrate resilience and an openness to be in a challenging workspace. One participant was concerned that Māori students who were placed within Iwi organisations would be too comfortable and therefore not push themselves.

Coming from a Māori organisation, an iwi organisation, and having Māori students coming in for placement, some of them tend to relax and want to kind of cruise along because they're more comfortable in an environment where they feel that they are safe and they tend to think, "Well I know everything", and this is only what I've picked up on some of them and we have mostly Māori students coming to us. So, I guess it's about getting them to step out of that comfort zone, making sure that they step out of the comfort zone and go into areas that they will end up going into when they go out into the workforce anyway, rather than just sit back and cruise.
There was also some discussion about whether there were differences between older and younger students:

I mean I've had a lot of adult students or older students, who are very clear about what they want to do, what area they're going to go to.

They're keen in their first placement, but they also tend to relax as well and I suppose that's a different sort of relaxation, they know that they're in their comfort zone, they know that they're in a safe zone, so you can get the best out of them then, but you also ... then you get students that are older, older students, who will just cruise.

These comments appeared to be in reference to particular students the participants had had on placement.

\section{Supporting Māori students to have a quality placement}

Participants were asked how tertiary institutions can best support a quality placement for Māori students. Themes were: Kanohi kitea-that the tertiary institution should be proactive and visible; that placement should be the students' sole focus; and that tertiary institutions have a responsibility to adequately prepare students.

\section{Kanohi kitea: A visible tertiary institution}

A quality placement, from these participants' perspectives, meant that the tertiary institution was visible, active and present. For instance, the institution should be involved in setting up the placement and attending the student welcome and poroporoaki (end of placement). This would support the integration of the student into the Māori community where they would be on placement. The participants also suggested increased placement visits by tertiary staff: 
...more visits from your coordinator, placement coordinator ... I think one at the beginning, maybe one in the middle and definitely one at the end, just to follow up, and if they're having problems at the start, you know.

I think that's one of the main things that in order to have quality it's to have all of those supports, to ensure that all those supports are there, they're solid, and they're there on a regular basis not just, you're there for say three months and they just ... your supervisor [tertiary staff] turns up halfway through. I really think that a supervisor needs to be, this is from ... [the institution] say that the supervisor needs to be there at least once a fortnight and keeping an eye on their student.

This active relationship was seen as particularly important for Māori students; for example one participant suggested that a handover should occur between the tertiary institution and the organisation at the beginning and at the end, not just a placement visit in the middle:

Yes. Taking in and taking out ... Well going into an environment. I'm just thinking in pōwhiri process and things like that ... So you're doing your pōwhiri and karakia and everything like that, you cover all of that part and then you leave them and then when it's time to finish you go back in and you do all of that process again to take them out, to take them home.

Participants discussed whether it would be appropriate for the tertiary institution to keep in contact with the organisation and student via email. While some participants agreed, others suggested that, in relation to Māori students, the ideal communication would occur face to face. The participants all emphasised that one visit half-way through the placement was insufficient.

\section{Placement the sole focus}

A number of the participants were adamant that students should focus solely on completing placement, and being actively present, instead of being distracted by additional course work:

When students are coming to placements that they should be finished everything and ready to go. I think it's really unfair that they're often having to do another paper or even two papers to the side. It diminishes the whole experience, so I really don't support how they do that now.

This was seen as particularly important for students in their final placement:

This is the last one and then they're out; finished. It would be great if they were actually coming in and everything was behind them and they could focus a hundred percent.

\section{Prepare the students}

The tertiary provider has a pivotal role preparing the student for their placement. Students should be prepared to participate in a pōwhiri or mihi whakatau, and all parties should take into account diverse Māori realities and knowledge of Te Ao Māori:

Do they need assistance with things like a pepeha or protocols and things around like a mihi whakatau or pōwhiri or what have you? Some of, you know, there's such diversity amongst Māori; some of them are coming in and they're at this level but others are $[$ not $] \ldots$

Participants also suggested improvements to the curriculum, such as having specialised courses so that the student has greater knowledge of the field of practice. This would be beneficial for the student and the placement organisation. It was noted that other professions had commented that students' lack of specific knowledge was 
surprising, suggesting specialisation in social work education.

The other thing that I think would be really useful here for [tertiary institution] to do is looking at the social work practicum as a whole, I understand why a lot of the stuff was generic, but when you're getting people going on placement, like to mental health or [care and protection] or social workers in schools or wherever they happen to be going...' cause a lot of students know what area of social work they want to go into and it's going to be helpful for organisations when you getting students who have studied in these certain areas, it's just going to be a better fit ... and it's going to help them more to get those jobs at the end if they were to do that ... So yeah, maybe a little bit of support there.

There were concerns that students were at times "thrown in the deep end" and ill-prepared to utilise Māori models of practice and to manage difficult and challenging situations like abusive parents or teenagers.

I've been told, at [tertiary institution] for example the students aren't even taught Te Whare Tapa Whā anymore. So in terms of what the institutes can provide, maybe they need to look at not just field practice but specific Māori models probably need to be introduced or reintroduced.

Another participant highlighted that when they were on placement there was confusion about the tertiary institution's assessment requirements:

I know of fellow students that have gone into placements and they haven't been given clear indication of what's expected as an outcome from that placement ... And they just didn't make it clear and a lot of people were getting told, "No. Go do it again."
This created unnecessary stress and some students had to resubmit work.

The findings reflect the participants' experience and commitment to enhancing the placement experience of Māori social work students. In particular, the participants identified the importance of clear expectations, open communication, the provision of a culturally safe environment, and challenging the student. They also spoke about the need for a visible tertiary institution, placement being the sole focus for students and the institution's role in preparing students.

\section{Discussion}

There is a case for considering field education differently for Māori students; this is evidenced in the literature and reinforced by the Māori social workers who participated in the hui. The participants demonstrated insight into the nuances involved in facilitating a placement that meets the particular needs of Māori students. Interestingly, their focus was less from their experience as students and more on their experiences as the supporting kaimahi, field educators and supervisors. Perhaps their current roles and experiences were easier to reflect on than reaching further back.

\section{Quality placements for Māori social work students}

A quality placement includes establishing expectations prior to the placement starting. Although placement preparation is universally important, it may be even more important for Māori students as they are often contending with a placement environment that is predominantly western. Further, there may be increased competition and reduced availability of placements if Māori students have particular needs or desire specific learning environments.

There are several factors that can assist with strengthening current pre-placement practice. This includes the tertiary provider 
and the placement host organisation meeting with the student prior to placement and discussing each other's expectations. This reduces the chance of misunderstandings which could lead to an unsuccessful placement. Putting more effort into the placement organisation process would help to create an environment of success and could enable other quality placement components to be explored, for example, whether the student is wanted and whether the student is suitable and ready (Hay, 2019).

Welcoming students in a culturally appropriate manner, such as with pōwhiri or mihi whakatau establishes a strong foundation for placement relationships. A robust orientation is also important as emphasised by Maidment (2000) who noted that Māori students rated orientation to the placement as important to their learning. In addition, orientation to placement is a key aspect of a successful placement as identified by Flanagan and Wilson (2018).

Growing the presence of Indigenous knowledge in field education and enabling a culturally safe environment for students is essential for quality placements (Gair et al., 2015; Moorhouse, 2014). Students should be supported to "be Māori" whilst also allowing space for their diverse realities. Some Māori students may not be confident in Māori spaces and may need additional assistance to prepare and practise. HollisEnglish's (2015) work supports that Māori social workers should be able to utilise their own cultural frameworks in practice. Interestingly, the research participants took more of a micro approach in their responses rather than a critical, macro approach taking into account wider systems and structural influences. Perhaps this was reflective of the nature of the questions asked, rather than an assumption of the absence of a critical lens.

One way to enhance Māori student placement experiences and to support their cultural needs is to place them in Iwi and Māori organisations. However, Māori students should still be challenged in their learning within an Iwi/Māori service. Creating stronger relationships between Iwi organisations and tertiary providers appears necessary. A consideration for future research could include examining how many tertiary providers place students in Iwi / Māori organisations and the different expectations and criteria amongst the providers.

In any placement, a key mechanism of support is supervision. If a Māori student is placed in a mainstream service, then additional support or external supervision could be provided by a cultural mentor/ supervisor, a Māori social worker and/or, as the participants mentioned, the tertiary institution. Matching Indigenous students with Indigenous mentors or supervisors could help to support a successful, quality placement (Aro, 2009; Gair et al., 2015; Moorhouse, 2014). Whilst a registered Māori social worker would meet the SWRB placement regulations, this does not preclude that additional cultural support could be provided by a non-social-worker with the necessary cultural skills and knowledge. Field educators or mentors could be screened for cultural suitability as suggested by Gair et al. (2015), although how this could be undertaken sensitively requires further thought. Ensuring that both Māori students and field educators / supervisors are prepared so that supervision is effective is also important (Lipsham, 2016). Whatever the approach taken, cultural and Kaupapa Māori supervision should be well-resourced by the tertiary institution (Moorhouse, 2014).

Participants noted that a student placement is more likely to be successful if the student is adequately challenged and able to work effectively in specific fields of practice such as care and protection and mental health. Social work qualifications in Aotearoa New Zealand are generic and this specific focus does not occur until post-qualification. The participant views signal a tension between what agencies may be expecting from students and what students, as learners, are able to contribute. Although it is 
not unexpected that agencies prefer students who can significantly contribute to their core work, field education is, by its very nature, a learning experience (Maidment, 2001). Further conversation and compromise may be required here, especially given the low numbers of Iwi / Māori placements and high numbers of students seeking placements (Hay, 2018; SWRB, 2018).

\section{Support from tertiary institutions}

The participants emphasised the level of contact and support that should be provided by the tertiary institution including involvement in a handover practice; attending the pōwhiri or mihi whakatau and then collecting the student at the conclusion of placement. Regular contact by the tertiary provider throughout the placement, with more than one midplacement visit-face to face was strongly suggested. Flanagan and Wilson (2018) also note the importance of regular support from the tertiary provider. This support could potentially include cultural supervision offered by the tertiary provider, and thereby address some of the concerns raised by Lipsham (2016) where she highlighted a gap in adequate bicultural supervisors for Māori social work students. This approach could give staff the opportunity to assist the student with any placement difficulties and work through their assessment requirements, avoiding the issues that occurred for some of the participants during their placements.

A further tension between the participant perspectives and some tertiary providers is the opportunity for students to have little to no other course work during their placement. Placements may already be a stressful time for students who juggle multiple responsibilities and potentially give up paid employment for the placement duration. Additional course work adds to these pressures. There may be pedagogical explanations for this, but more research needs to be undertaken to identify the issues and tensions here. Examination of completion rates may also be useful. Gair and Baglow (2018) and Aro (2004) particularly noted the susceptibility of Indigenous students to stress while undertaking placement, especially financially. In Aotearoa New Zealand, the NGO study awards had a high uptake by Māori social work students who were able to work towards a social work qualification whilst maintaining their jobs and connections to their whānau and communities (Yeung et al., 2016; Yeung et al., 2019). Reintroducing these awards for the social work sector would be of considerable benefit for many future students. Finally, tertiary providers should continue to review curriculum design and how it may disadvantage Indigenous students and consider ways to enhance their learning experience.

\section{Conclusion}

Overall, this research presents a challenge for tertiary institutions to actively reflect on what quality placements are for Māori social work students. In particular, attention should be given to curriculum design, placement preparedness, cultural support and tertiary provider interaction with agencies. A critical, decolonised and intersectional approach is recommended.

Accepted 2 September 2020

Published 3 November 2020

\section{References}

Aro, C. L. (2004). Indigenous social work student experiences in the child welfare specialization: Exploring the field education encounter. University of Victoria.

Bogo, M. (2010). Achieving competence in social work through field education. Toronto, ONT: University of Toronto Press.

Clark, N., Drolet, J., Mathews, N., Walton, P., Tamburro, P., Derrick, J., ... Arnouse, M. (2010). Decolonizing field education: "Melq'ilwiye" coming together: An exploratory study in the interior of British Columbia. Critical Social Work, 11(1). Retrieved from https://ojs.uwindsor.ca/ index.php/csw/article/view/5812/4743

Clark, N., Reid, M., Drolet, J., Walton, P., Peirce, J., Charles, G., ... \& Arnouse, M. (2012). Indigenous social work field education: "Melq'ilwiye" coming together towards reconciliation. Native Social Work Journal, 8, 105-127. 
Cleak, H., \& Wilson, J. (2018). Making the most of field placement. Cengage.

Cunningham, C. (2000). A framework for addressing Māori knowledge in research, science and technology. Pacific Health Dialog, 7(1), 62-69.

Douglas, J. (2011). Developing kia tene/off the cuff-A resource for field educators in social work in Aotearoa New Zealand. Aotearoa New Zealand Social Work, 23(4), 34-44.

Eketone, A., \& Walker, S. (2016). Kaupapa Māori social work research. In M. Gray, J. Coates, M. Yellow Bird, \& T. Hetherington. Decolonizing social work (pp. 259-270). Routledge.

Flanagan, N., \& Wilson, E. (2018). What makes a good placement? Findings of a social work

student-to-student research study. Social Work Education, 37(5), 565-580.

Gair, S., \& Baglow, L. (2018). "We barely survived" Social work students' mental health vulnerabilities and implications for educators, universities and the workforce. Aotearoa New Zealand Social Work, 30(1), 32-44.

Gair, S., Miles, D., Savage, D., \& Zuchowski, I. (2015). Racism unmasked: The experiences of Aboriginal and Torres Strait Islander students in social work field placements. Australian Social Work, 68(1), 32-48.

Gladstein, M. \& Mailick, M. (1986). An affirmative approach to ethnic diversity in field work. Journal of Social Work Education, 22(1), 41-49.

Hay, K. (2018). "There is competition": Facing the reality of field education in New Zealand. Aotearoa New Zealand Social Work Journal, 30(2), 16-27.

Hay, K. (2019). "It's a whole orchestra": What are the instrumental elements in quality field education? Social Work Education, 39(4), 417-429. doi:10.1080/026 15479.2019.1651261

Hollis-English, A. (2015). Theories in Māori social work: Indigenous approaches to working with and for indigenous people. Aotearoa New Zealand Social Work, 27(4), 5-15. http://dx.doi.org/10.11157/anzswjvol27iss 4 id432

Kanno, H., \& Koeske, G. (2010). MSW students' satisfaction with their field placements: The role of preparedness and supervision quality. Journal of Social Work Education, 46(1), 23-38.

Lipsham, M. J. H. (2016). He kohinga kōrero ā ngā kaiarataki me ngā kaiako: student supervision: experiences and views of kaiarataki and kaiako at Te Wānanga o Aotearoa (Masters' thesis). Massey University, Manawatū, New Zealand.

Maidment, J. (2000). Methods used to teach social work students in the field: A research report from New Zealand. Social Work Education, 19(2), 145-154.

Maidment, J. (2001). Teaching and learning social work in the field: Student and field educator experiences. Social Work Review, 13(2), 2-6.

Māori Dictionary. (2019). Retrieved from https:// maoridictionary.co.nz/search?idiom $=\&$ phrase $=\&$ proverb $=$ \&loan=\&histLoanWords=\&keywords $=$ hui

Moorhouse, L., Hay, K., \& O'Donoghue, K. (2014). Listening to student experiences of supervision. Aotearoa New Zealand Social Work, 26(4), 37-52.
Social Workers Registration Board (SWRB). (2019). SWRB programme recognition standards. Retrieved from https://swrb.govt.nz/about-us/policies/

Tertiary Education Commission. (2020). SAC level 3 and above funding rates. https://www.tec.govt.nz/funding/ funding-and-performance/funding/fund-finder/studentachievement-component-provision-at-level-3-and-aboveon-the-nzqf-fund/sac-funding-rates/

Watson, A. (2019). Collision: An opportunity for growth? Māori social workers' collision of their personal, professional, and cultural worlds and the values and ethical challenges within this experience. Journal of Social Work Values and Ethics, 16(2), 28-39.

Yeung, P. H. Y., Mooney, H., \& English, A. (2016). Nongovernment Organisations (NGO) study awardsExploring the impact on social work students and social service organisations. Technical Report. School of Social Work. Palmerston North: Massey University.

Yeung, P., Mooney, H., English, A., \& O'Donoghue, K. (2019). Non-government organization study awards: enhancing successful completion of social work qualification, Social Work Education. doi:10.1080/02615 479.2019.1696293

Zuchowski, I., Savage, D., Miles, D., \& Gair, S. (2013). Decolonising field education: challenging Australian social work praxis. Advances in Social Work and Welfare Education, 15(1), 47-62. 